\title{
Adaptive Interaction Design for Online Mathematics Education: The Way of the Game
}

\author{
Daniel J. Franklin \\ Department of Cognitive and Neural Systems, Boston University \\ Six Red Marbles, USA
}

\begin{abstract}
Together, brain science and learning design inform Adaptive Interaction Design (AID), a technique for curriculum planning and development. Mathematics is a particular case in which AID can help. The Way of the Game is vital to learning design. There are many definitions of "game." Here, we mean game to be the means by which spontaneous play becomes responsible learning. That innovative games figure as the centerpiece of many 21 st century curricula is no accident. Games are a critical element in modern theories of learning design especially when related to insights from neuroscience and online learning/teaching methods. But beyond simple gamification, can games provide the disruptive transformation to mathematics education that is required to effect substantive and sustainable improvement? Can we game the educational system to ensure students' success in mathematics? To find out, we will look at the AID process and two sample products for the development of mathematical thinking and practice based on the Way of the Game.
\end{abstract}

\section{Introduction}

How can we build confidence and competence in children as they start to learn mathematics in formal educational environments? As their natural behavior shows, very young children and many nonhuman animals have a sense of number as magnitude or direction; however, only humans use a symbol system to represent the concept of number [9]. How can learning design maintain a sense of the wonder and joy of learning, minimize math anxiety, and improve performance on standardized tests? Can technology provide supporting answers to these questions?

Practical insights from design [18] and educational and neuroscience research $[5,9,13]$ have helped develop Adaptive Interaction Design (AID). Because it uses real-time data to meet students where they are and thereby differentiate instruction, AID is at the core of adaptive curriculum. At Six Red
Marbles (SRM), Natural Learning ${ }^{\mathrm{TM}}$ is the approach to curriculum design that is sensitive to why we learn, what we learn, when we learn, how we learn, and where we learn. To see AID in action, we will look at $\mathrm{Waza}^{\mathrm{TM}}$ and Cabanga ${ }^{\mathrm{TM}}$, two online learning programs for mathematics education from SRM.

\section{Neuroscience research and education}

How can mathematics education for early learners be improved? Educational neuroscience provides some answers. Literature from the Science of Learning includes studies on perception, visual and auditory attention, short and long-term memory, sequence learning, the role of novelty in motivation and learning, emotion/anxiety, concept and rule formation, how people learn mathematics and language, and linguistic, procedural, and kinesthetic learning and performance. Many results from these studies have already been applied with success [15].

Educational neuroscience consists of basic research and applications to curriculum, pedagogy, teacher training, and social policy. Similar to the practice of medicine, it looks at symptoms and prescribes treatments. Major areas of potential impact are in reading and dyslexia, number sense and dyscalculia, attention, emotion and social cognition. For example, the issue of left versus right brained learning is a matter of emphasis and not a firm fact; in normal brains, the two hemispheres continually interact in parallel and complementary ways. In a complete model of learning, development of leftbrain skills that depend on sequential action and thought (reading, writing and arithmetic) must be complemented by development of the holistic, creative processes by means of right-brained activities such as visual support, story-telling, and role playing.

Whole brain learning is the natural way people learn. Effective AID components for educational exchanges balance the traditional approach with an innovative approach to education. Some people think of this dichotomy as a left-brain versus right brain issue; however, that is a false dichotomy. Nevertheless, the differences between analytical sequential thinking on the one hand and synthetic 
holistic thinking on the other are real and need to be addressed in curriculum design.

Neuroscience research can help to improve curriculum. For example, psychophysical experiments on effects of visual crowding on eye movements and object identification prove that uncluttered visual presentations can better direct attention. Additionally, how fast and how many successive attention shifts occur will affect the eye muscle and can cause physical and cognitive fatigue. Such laboratory research [11] helps to quantify parameters of size or spacing of visual elements in order to help curriculum designers produce more effective on-line materials.

Although all neuroscience research is not directly applicable to educational improvement, it is clear that it will continue to yield results that will be relevant. Highlights of guiding research for AID include the following:

- Using the whole brain for learning is optimal.

- Multiple types of learning can support performance and creativity.

- Previous knowledge influences on-going learning - for better or worse!

- Humans are naturally inquisitive and motivated by novelty.

- Emotion directly impacts perception, cognition, and action.

- Social interaction is critical to developing attention.

- Exercising memory develops awareness.

- Assessment embedded in adaptive curriculum is efficient and effective.

- Real-time data supports optimal decisions.

- Effective educational technology has a simple, clutter-free, intuitive interface.

\section{Emotional development and function}

What does the psychobiology of emotion tell us about instructional design? Effective instructional design (curriculum \& pedagogy) needs to take into account the dynamics of emotion in real-time by addressing multiple modes of learning (verbal, visual, tactile) and providing timely adaptive feedback. Therefore, AID includes understanding emotions as well as basic cognitive capabilities and performance benchmarks. The emotional psychodynamics for readiness, flexibility, and motivation that inspire AID are summarized in Figure $1[15,16]$.

Let us explore some of the interactions among emotions that are modeled in Figure 1 as they relate to young learners. Children are naturally inquisitive, social beings. Motivated hands-on learning is fundamental to their interaction with the world. Seeking is a natural behavior that is stimulated by its own reward- novelty. Discovery involves looking at things from different perspectives using multiple sensory modalities. Discovery engagement is crucial to product design. Seeking is supported by and also supports activities related to play (motor, cognitive and social) and care (receiving and giving); all three are contrary to the destructive qualities of anger. However, seeking may lead to fear or panic/grief which in turn may lead to anger; unfortunately, anger inhibits not only fear and panic/grief but seeking as well. Fear upsets cognitive, perceptual and autonomic processes. The reaction is fight, flight, or freeze. You can follow several such interactions in the chart.

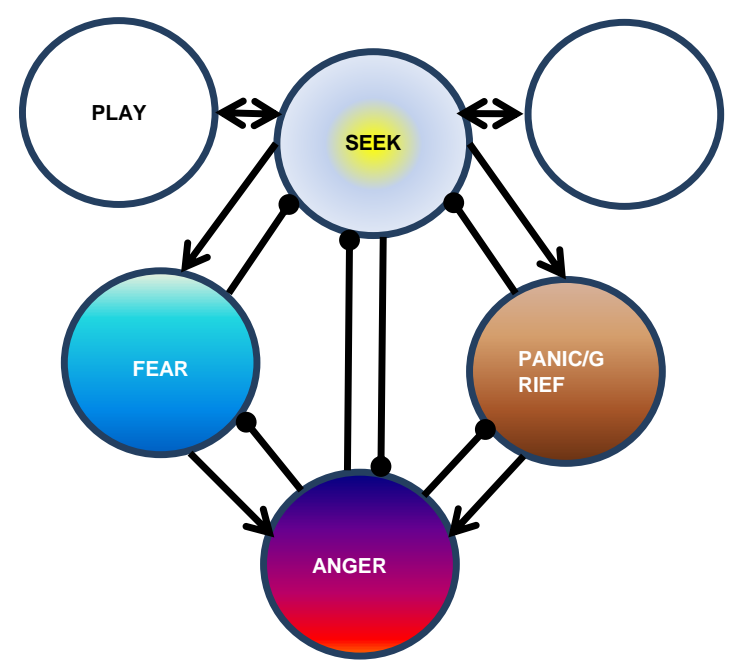

Figure 1. A simplified model of the dynamics of innate emotional systems in the classroom (adapted from

[16]). Arrows indicate activation; circles indicate inhibition

Unless fear, panic/grief, and anger are managed, seeking, play, and care will be unfulfilled. It is well known that behavioral responses to emotions can be learned and un-learned [13]. The dynamic interplay of emotions has direct application to AID for instruction (see Table 1).

\section{Mathematics education with AID}

Learning mathematics depends on abilities that are found in many species: visual recognition of objects, visual and motor place value, estimating and comparing sets of objects, and 1:1 correspondence $[19,20]$. With this foundation, children learn higher mathematics. A helpful framework of learning about mathematical representations ranges from qualitative to quantitative models; that is, from physical 
Table 1. Examples of instructional design by the management of emotions during learning interactions

\begin{tabular}{|c|c|c|}
\hline GOAL & $\begin{array}{c}\text { INSTRUCTIONAL } \\
\text { DESIGN }\end{array}$ & $\begin{array}{l}\text { RELATED } \\
\text { OUTCOMES }\end{array}$ \\
\hline $\begin{array}{l}\text { Increase } \\
\text { SEEK }\end{array}$ & $\begin{array}{l}\text { Engage students' } \\
\text { current knowledge; } \\
\text { develop motivation and } \\
\text { joy of learning through } \\
\text { novelty and adaptive } \\
\text { curriculum with } \\
\text { immediate feedback. } \\
\text { Increase PLAY and } \\
\text { CARE. }\end{array}$ & $\begin{array}{l}\text { Reduced FEAR, } \\
\text { PANIC/GRIEF } \\
\text { \& RAGE }\end{array}$ \\
\hline $\begin{array}{l}\text { Reduce } \\
\text { FEAR }\end{array}$ & $\begin{array}{l}\text { Increase opportunities } \\
\text { for success; discuss } \\
\text { anxiety. Increase } \\
\text { CARE. }\end{array}$ & $\begin{array}{l}\text { Increased SEEK, } \\
\text { PLAY, and } \\
\text { CARE }\end{array}$ \\
\hline $\begin{array}{l}\text { Reduce } \\
\text { PANIC/ } \\
\text { GRIEF }\end{array}$ & $\begin{array}{l}\text { Social contact; planned } \\
\text { interactions with peers, } \\
\text { teachers, parents. Use } \\
\text { Cooperative Learning, } \\
\text { and Peer Interaction. } \\
\text { Increase CARE. }\end{array}$ & $\begin{array}{l}\text { Increased SEEK, } \\
\text { PLAY, and } \\
\text { CARE }\end{array}$ \\
\hline $\begin{array}{l}\text { Reduce } \\
\text { RAGE }\end{array}$ & $\begin{array}{l}\text { Channel energy into } \\
\text { play and games such as } \\
\text { software/video games } \\
\text { with embedded learning } \\
\text { objectives. Increase } \\
\text { PLAY and CARE. }\end{array}$ & $\begin{array}{l}\text { Increased SEEK, } \\
\text { PLAY, and } \\
\text { CARE; reduced } \\
\text { RAGE, FEAR \& } \\
\text { PANIC/GRIEF }\end{array}$ \\
\hline
\end{tabular}

representations similar to reality to increasingly abstract, mathematical representations in which numbers and algebraic variables represent measurable dimensions of reality [17]. In order to properly scaffold new instruction and maximize learning, the teacher must first find out what students know about the content, then present relevant models for new learning in actions, pictures, and diagrams and other qualitative methods and models. As quantitative skills mature, the learner is exposed to increasingly complex symbolic representations and relationships. Therefore, remediation of children's difficulties with learning mathematics can be related to one or more of several potential sources of difficulty. Remedial goals typically include improvements in long-term memory, short-term processing speed, and performance accuracy [cf. 4].

As neuroscience has found layers of parallel and complementary processes in the brain, and cognitive psychologists have found corresponding functions of the mind; thus, a variety of experiences need to be designed with complementary pedagogical approaches such as lecture/discovery, quantitative/qualitative, and outcome/process. Technology can support these varied experiences.

Waza $^{\mathrm{TM}}$ (Zulu for think) is an on-line learning game developed with AID for elementary school students (see Figure 2). Immersed in a participative adventure story, the child interacts with $\mathrm{Waza}^{\mathrm{TM}}$ in a layered manner: the first layers require no previous background, while later layers introduce increasingly advanced activates. Immediate feedback is provided, and animations that provide instructional coaching are optional. A unique user interface was developed to support the hierarchy of ways people learn math at any level of the subject:

- Intuitive (perceptual and prior knowledge)

- Concrete (use of physical models)

- Verbal (vocabulary of quantities \& relationships)

- Concepts (computational thinking)

- Pictorial (draw and interpret models)

- Abstract (use symbols to represent ideas)

- $\quad$ Procedures (distributed practice)

- Application (use concepts \& procedures on new problem)

- $\quad$ Communication (describe; explain; collaborate; share)

- $\quad$ Assessment (formative: during chunked \& distributed practice; using technology, assessment becomes an adaptive gateway to the next learning experience.)

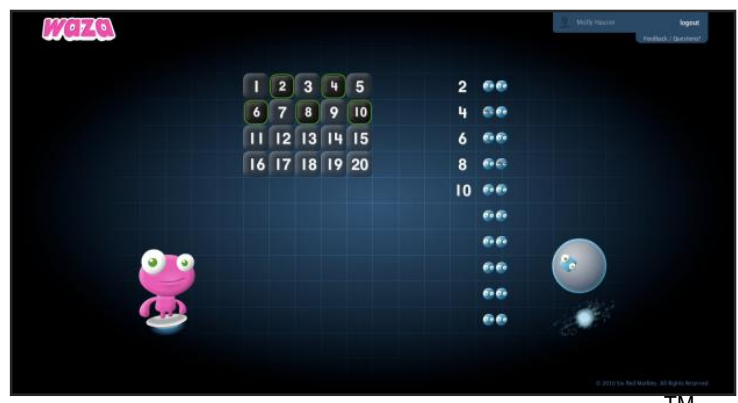

Figure 2. Helping children count by $2 \mathrm{~s}, \mathrm{Waza}^{\mathrm{TM}}$, makes heroes out of those who focus and solve problems

Cabanga $^{\mathrm{TM}}$ (Zulu for imagine) is an online learning game developed with AID that makes middle school math relevant and fun (see Figure 3). Students role-play as celebrity talent agents, applying core math concepts, methods, principles and techniques to achieve business success. Cabanga ${ }^{\mathrm{TM}}$ combines tribal pedagogy (learning by necessity, imitation and story-telling) and learning design principles based cognitive neuroscience research. Cabanga $^{\mathrm{TM}}$ to build 21st Century skills using projectbased learning, including critical and computational thinking, problem solving, analyzing information and entrepreneurialism. An in-game leader board breeds healthy competition. 


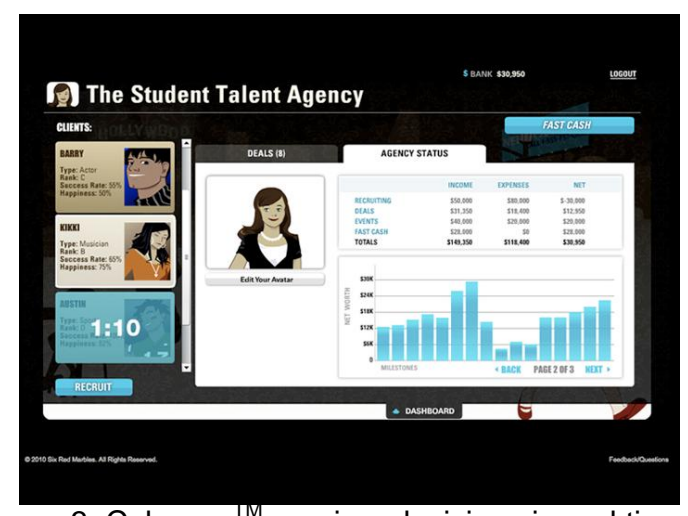

Figure 3. Cabanga ${ }^{1 \mathrm{M}}$ requires decisions in real time based on understanding probability

With layered curricula, both $\mathrm{Waza}^{\mathrm{TM}}$ and Cabanga $^{\text {TM }}$ support a component-based, topical structure that allows just-in-time delivery of curriculum to match student interest and readiness. The SRM Natural Learning ${ }^{\mathrm{TM}}$ approach supports the development of a deep understanding of mathematics due to adaptively leveraging prior knowledge, expectations and motivations with AID. Using technology for ease of access, these programs are accessible via the Internet anytime, anywhere.

\section{Gaming the system: Technology and education in the $21^{\text {st }}$ century}

Consider the design elements of the game that make it fun: can they be applied to mathematics education? In 1999, Doug Church outlined three design elements as an initial step of the development of general design principles for games. The first design element in the game is the story- the context for the goals of the game. In curriculum design, the story includes student development. Story motivates; self-awareness is an intrinsic reward related to a sense of control and power. The second design element is intention or self-fulfilling motivation. In curriculum design, intention must be supported by the learning materials. The third design element is a perceivable consequence of action based on rules of the game and the game-delivery technology. In curriculum design, clear consequences and constancy of response includes the teacher interaction as a source of stable formative feedback. Yes, general design elements for games can be applied to curriculum development in general, and mathematics education in particular [7].

On a deeper level, we can point to the common features of the social and cognitive neuroscience behind play, games and learning. Based in technology, or other media, games require communication among the players. Joint attention is a powerful leaning experience, and one to which every classroom teacher aspires to bring to each individual student. Based on novel ways of applying rules, games allow play; understanding the rules allows one to play the game. Games often lead to goals that are stated or discovered. Learning the rules make the attainment of the game goals possible. Well-designed games make learning fun because they provide an experience of competence. Not too hard; not too easy. In addition, the large cognitive load inherent in the game is managed through the game design and the motivated attention of the player. When instructional design takes account of the rules of cognition performance can be optimized $[2,3,4,5]$. The resulting confidence is a gamechanger for previously unengaged students.

Games involve pattern recognition and problem solving. Pattern recognition includes the classification of novel entities, based on prior learning. This type of cognitive task is critical in learning language, math, and facts about the world. Classification typically requires that a choice be made, and then feedback can be provided. More complex problem solving requires that multiple choices be made before feedback arrives. Since most learning is sequence learning, breaking down a complex cognitive task into its sub-tasks would allow more specific feedback, quicker error correction, and faster learning. Students would thereby improve their capability to do pattern recognition and problem solving.

To experience how your expectations impact your interpretation of sensory input, play with the Charlie Chaplin mask which is posted at http://www.youtube.com/watch?v=QbKw0_v2clo.

What changed as you listened to the narrator? The mask, its movement, or your interpretation of what you think you saw? Did you see what was really there at all times, or did you create some of it? The normal processes of perceptional input and recognition are in fact controlled considerably by top-down-expectations based on prior experience and learning. Seeing is believing! This idea goes well beyond curriculum scaffolding. It points to the way the brain is organized so that it can learn new things while being able to remember previous ones. Finally, did you see the man in the mirror? After all, to rephrase the bard, “...play is the thing wherein we'll catch the conscience of the student." And conscience is built upon awareness and attention, a.k.a. consciousness. Games are a natural means to engage students and direct their attention so they become self-aware learners who develop the intellectual, emotional, and social skills required of people in the $21^{\text {st }}$ century.

If you would like to read more about game and technology design to stimulate your thinking about how they may impact curriculum development and learning design, I recommend the comprehensive work by Katie Salen and Eric Zimmerman [18]. Designing Interactions (2007) by Bill Moggridge is 
another excellent resource [14]. It is a profusely illustrated collection of interviews with 40 influential digital designers from different fields in the historical context of how they identified and solved various interaction design problems.

\section{But will it work?}

Much has been written about the promise and peril of technology in education. An interesting view is that technology is a tool for knowledge construction, rather than merely knowledge storage and retrieval. This view promotes the tight-coupling of technology in both the educational process and outcome for both the students and the teachers. The Education Arcade at MIT has proposed a useful typology about how to ensure the success of technology adoption projects in educational institutions: the key determinants are the school, the teacher, the technology itself, and the students [12]. Ratings of the context, the innovator, the innovation, and the operator, and how they fit together and might interact, can be used on multiple scales, within a classroom, or for a district of schools. The authors include a detailed ratings checklist with qualitative descriptions to help the assessment along with suggestions for use in the field. Their references section contains citations of relevant work in the field technology, games, and education.

The design of digital learning environments needs to address the student's ability to learn sequences as well as make complex decisions. AID is critical for product usability and learning unfamiliar sequence of action [1]. Research that informs specific visual displays also provides important design constraints: a simple, clutter-free, intuitive interface, increases engagement with the activity. Too often, educational technology is cluttered and ineffective.

With these points in mind, WazaTM was designed to technology to leverage effective patterns of cognitive-emotional interaction that are essential to long-term memory and learning. Cabanga ${ }^{\mathrm{TM}}$, the role-playing simulation game that allows students to make decisions under uncertainty in a problem solving context, motivates students try many math topics which are not always easy to master (see Figure 4)

. Software is an important tool for motivating students, as well as collecting data and supporting analysis by the teacher or by the students themselves. The teacher administration feature is an important part of both learning environments.

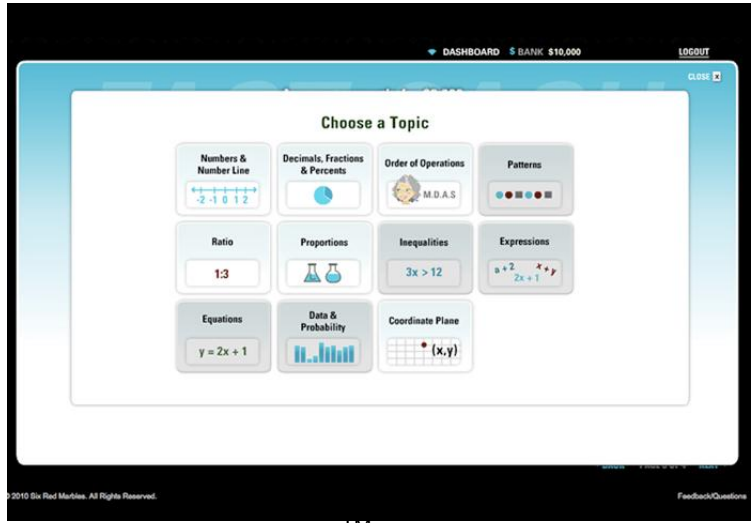

Figure 4. Cabanga "motivates doing math

\section{Cybernetics- the way of the learning organization}

Over the last 60 years, there have been several discussions of how cybernetics can help provide quality education of individuals and organizations. The word cybernetics comes from Greek for the person who steers a ship or the rudder itself. Simply put, cybernetics is the science of control and studies the interactions among components in a system. It was first used by Norbert Wiener in applying mathematical feedback models to control large guns during WWII. Since then, cybernetics has been extended to the social sciences as a theory that all parts which comprise a whole can impact the whole; in particular, how information derived from a system can be used to make changes to that system. Nowadays, we call this data-driven management.

After Ross Ashby introduced cybernetics to England, cybernetics was extended from physical, biological and psychological applications to other areas of human endeavor. Papers were written about organizational cybernetics as an unsupervised, natural flow of events, as well as more supervised cybernetic techniques of change such as teaching methods, teaching machines, learning, adaptive systems, education, human performance, and organizational memory and control systems to create a learning organization. The discussion focused on the use of computers to provide assessment and instruction as well as administrative processing and planning. Nowadays, we call these learning management systems.

Now, we witness innovative, $21^{\text {st }}$ century learning environments that are creating the future. These schools are learning organizations in the sense that they have the ability for real-time adaptation and capacity for continual transformation. So who or what is actually steering schools to become learning organizations? In cognitive science, there are notions of unsupervised and supervised modes of learning. Cybernetics reduces them both to a matter of 
feedback and control. The reason why real-time, formative assessments are so critical is that they 1) build trust between giver and receiver and 2) specific content is given as close to the time of the error as possible so that adjustments can be made right away. Yes, summative assessments that measure long-term leaning are still important; but there is no long-term memory formation without short-term memory storage and rehearsal. Cybernetic education makes sure the rehearsal is the right rehearsal for both individuals and organizations

\section{Summary and concluding remarks}

The whole brain is always engaged whether curriculum is designed primarily for the left-brain, the right-brain, or the whole mind/brain/body, In this light, AID incorporates best practices that support how people learn [3]:

(1) start with students' previous knowledge and misconceptions,

(2) follow an explicit curriculum structure with progressive formalization and use of symbols to promote deep understanding, application, transfer, and communication,

(3) contain integrated assessment that includes both formative (continual, interactive) as well as summative feedback, and

(4) teach relevant topics which can be applied to everyday experience and problem solving.

Too often the sequence of math curriculum does not match the cognitive development of the child so the task is difficult. Within a fun context of play and adventure, Waza ${ }^{\mathrm{TM}}$ provides practice with the vocabulary, concepts and procedures necessary for long-term success in mathematics. The multi-media adaptive curriculum supports short-term achievement as well as long-term memory and learning. Engaging activities for using positional and relational vocabulary, recognizing quantities visually, sequencing, counting and more are included to support young children learning math.

Neuroscience has a varied and large literature related to motivation, values, and decision-making. How does awareness and self-consciousness lead to conscience? How do members of teams cooperate and compete? How can new curriculum/pedagogy support development of both the individual and society? Neuroscience can inform issues related the heart of education; AID can leverage the results with the Way of the Game.

\section{References}

[1] Agam, Y., Bullock D., and Sekuler, R. (2005). Imitating unfamiliar sequences of connected linear motions. Journal of Neurophysiology 94, 2832-2843.

[2] Bradski, G., Carpenter, G.A., and Grossberg, S. (1994). STORE working memory networks for storage and recall of arbitrary temporal sequences. Biological Cybernetics $71,469-480$.

[3] Bransford, J. D., Brown, A. L., and Cocking, R. C., editors (2000). How People Learn: Brain, Mind, Experience, and School. National Academy Press: Washington, D.C. .

[4] Cowan, N., Chen, Z., and Rouder, J. N. (2004). Constant capacity in an immediate serial-recall task: A logical sequel to Miller (1956). Psychological Science 15, 634-640.

[5] Crawford, K. (1996). Vygotskian approaches to human development in the information era. Educational Studies in Mathematics 31, 43-62.

[6] Dahaene, S. (1997). The Number Sense: How the Mind creates Mathematics. Oxford: Oxford University Press.

[7] Devlin, K., (2011). Mathematics Education for a New Era: Video Games as a Medium for Learning. A K Peters, London, GB.

[8] Felisbert, F.M., Solomon J.A., and Morgan M.J. (2005). The role of target salience in crowding. Perception 34(7), 823-33.

[9] Franklin, D.J. (2008). Interactive Curriculum Based on Models of Mind \& Brain. Brains, Minds, and Media, Vol.3, bmm1418, in: Lorenz S, and Egelhaaf $M$ (Eds.): Interactive Educational Media for the Neural and Cognitive Sciences. Brains, Minds \& Media.

[10] Franklin, D.J. and Grossberg, S. (2008). Cognitiveemotional learning by neocortex, amygdala, and hippocampus: Timing, neurotrophins, amnesia, and consciousness. In Proceedings of the Twelfth International Conference on Cognitive and Neural Systems (ICCNS), Boston University, May.

[11] Goswami, U. (2006). Neuroscience and education: from research to practice? Nature Reviews Neuroscience April, 2-7.

[12] Klopfer, E., Osterweil, S., Groff, J., and Haas, J. (2009). "The instructional power of digital games, social networking and simulations and how teachers can leverage them." The Education Arcade: Massachusetts Institute of Technology.

http://education.mit.edu/papers/GamesSimsSocNets_EdAr cade.pdf (Access date: 29/2/2010).

[13] LeDoux, J.E. (1993). Emotional memory systems in the brain. Behavioural Brain Research, 58, 69-79.

[14] Moggridge, B. (2007). Designing Interactions. MIT Press: Cambridge, MA.

[15] Panksepp, J. (1998). Affective Neuroscience: The Foundations of Human and Animal Emotions. Oxford University Press: USA.

[16] Panksepp, J. and Biven, L. (2012). The Archeology of Mind: Neuroevolutionary Origins of Human Emotions. W. W. Norton \& Company: New York, NY.

[17] Petrosino, A. (2003). "Commentary: A framework for supporting learning and teaching about mathematical and scientific models." Contemporary Issues in Technology and Teacher Education 3(3), 288-299. 
[18] Salen, K. and E. Zimmerman (2004). Rules of Play: Game Design Fundamentals. MIT Press: Cambridge, MA.

[19] Wilson, A.J., Dahaene, S., Pinel, P., Revkin, S.K., Cohen, L., and Cohen, D. (2006). "Principles underlying the design of 'The Number Race,' an adaptive computer game for remediation of dyscalculia." Behavioral and Brain Functions 2(19), 1-14.

[20] Whyte, J.C., and Bull, R. (2008). "Number Games, Magnitude Representation, and Basic Number Skills in Preschoolers." Developmental Psychology 44(2), 588-596. 